\title{
The Association Between Patient Characteristics and the Therapeutic Alliance in Cognitive-Behavioral and Interpersonal Therapy for Bulimia Nervosa
}

\author{
Michael J. Constantino, Bruce A. Arnow, Christine Blasey, and W. Stewart Agras \\ Stanford University Medical Center
}

\begin{abstract}
The therapeutic alliance is an established predictor of psychotherapy outcome. However, alliance research in the treatment of eating disorders has been scant, with even less attention paid to correlates of alliance development. The goal of this study was to examine the relation between specific patient characteristics and the development of the alliance in 2 different treatments for bulimia nervosa $(\mathrm{BN})$. Data derive from a large, randomized clinical trial comparing cognitive- behavioral therapy (CBT) and interpersonal therapy (IPT) for BN. Across both treatments, patient expectation of improvement was positively associated with early- and middle-treatment alliance quality. In CBT, baseline symptom severity was negatively related to middle alliance. In IPT, more baseline interpersonal problems were associated with poorer alliance quality at midtreatment.
\end{abstract}

The patient-therapist relationship has become one of the most frequently identified-and studied - common factors in psychotherapy (see Constantino, Castonguay, \& Schut, 2002; Horvath \& Bedi, 2002). The therapeutic alliance, which reflects patienttherapist collaborative engagement in the therapy process in the context of an affiliative attachment (e.g., Bordin, 1979; Castonguay \& Constantino, in press; Horvath \& Bedi, 2002), is a consistent predictor of patient improvement across a variety of psychotherapies and clinical problems (see Constantino et al., 2002). Based on several meta-analytic reviews, effect sizes-as estimated by the weighted correlation coefficient $r$-for the allianceoutcome association have ranged from .22 to .26 (Horvath \& Bedi, 2002; Horvath \& Symonds, 1991; Martin, Garske, \& Davis, 2000).

Although substantial evidence highlights the global allianceoutcome association, far less is known about factors contributing to the development of a quality alliance (Horvath \& Bedi, 2002; Norcross, 2001). Without a greater understanding of such factors, findings relating alliance to outcome will be of limited use to the practitioner (Constantino, 2000; Horvath, 1994). Thus, it is important to identify patient characteristics that are associated with the alliance so that therapists can better forecast potential relationship ruptures and alter their interventions accordingly (Horvath, 1994; Muran, Segal, Samstag, \& Crawford, 1994; Safran, Muran, Samstag, \& Stevens, 2002). The objective of the current study was to

Michael J. Constantino, Bruce A. Arnow, Christine Blasey, and W. Stewart Agras, Department of Psychiatry and Behavioral Sciences, Stanford University Medical Center.

Preparation of this article was supported in part by National Institutes of Health National Research Service Award 5 T32 MH19938 -10 awarded to Michael J. Constantino. We are grateful to Susan Bryson for her help in conducting this study.

Correspondence concerning this article should be addressed to Michael J. Constantino, who is now at the Department of Psychology, Tobin Hall, 135 Hicks Way, University of Massachusetts, Amherst, MA 01003-9271. E-mail: mconstantino@psych.umass.edu examine the link between patient characteristics and the alliance across two distinct treatments for bulimia nervosa: cognitivebehavioral therapy (CBT) and interpersonal therapy (IPT). Few studies on the treatment of eating disorders have examined the relation between the alliance and outcome, and none have examined correlates of alliance formation. Therefore, our hypotheses were informed by research focused on other clinical populations. The work in this area has shown several patient characteristics to predict the alliance, including treatment expectancies, interpersonal functioning, and symptom severity (e.g., Connolly Gibbons et al., 2003; Meyer et al., 2002; Raue, Castonguay, \& Goldfried, 1993).

According to goal theories (e.g., Austin \& Vancouver, 1996; Carver \& Scheier, 1998), people will work toward a goal as long as they expect that the goal can be reached. Without such positive expectation, the person is likely to become discouraged and to disengage from pursuing the goal. For example, a patient who expects to improve may be more likely to engage in the treatment process, including developing a collaborative, affiliative bond with his or her therapist, than a patient who holds little hope for change (Meyer et al., 2002). Consistent with this perspective, Connolly Gibbons et al. (2003) found that patients' pretreatment expectation of improvement predicted patient-rated early alliance quality in supportive- expressive therapy for a heterogeneous patient sample as well as patient-rated middle alliance quality across both supportive- expressive and cognitive therapy for the same sample. In addition, Meyer et al. (2002) found that patients' pretreatment expectation of change was positively associated with patient-rated early alliance across various treatments of depression. In a study of time-limited dynamic psychotherapy for a heterogeneous patient sample, Joyce and Piper (1998) found that patients' expectation of session usefulness was positively associated with patient-rated alliance for the same session. Moreover, Joyce, Ogrodniczuk, Piper, and McCallum (2003) found that patients' pretreatment rating of expected improvement for their own target objectives significantly predicted patient- and therapist-rated alliance quality (aggregated across all sessions) in time-limited therapy for heterogeneous conditions. 
The relation between difficulties in interpersonal functioning and the therapeutic alliance has also been investigated. Several studies have revealed a negative association between interpersonal problems and alliance formation. Connolly Gibbons et al. (2003) found that hostile-dominant interpersonal problems predicted poorer middle alliance in both supportive- expressive and cognitive therapies. Similarly, Muran et al. (1994) found that hostiledominant interpersonal problems were negatively related to aspects of the alliance (i.e., task and goal agreement) measured early in cognitive therapy. Moreover, Marmar, Weiss, and Gaston (1989) found that having more problems in pretreatment interpersonal functioning was associated with worse alliance formation in bereaved patients receiving psychodynamic treatment. Thus, evidence suggests that the patient-therapist bond is negatively influenced by patients' baseline interpersonal problems across a variety of psychotherapies.

Studies examining the relation between patient symptom severity and the development of the therapeutic alliance have produced mixed results (Horvath \& Bedi, 2002). In a study of psychodynamic-interpersonal therapy, Raue et al. (1993) found that patients' subjective distress was negatively associated with observer-judged alliance. In a naturalistic study, ${ }^{1}$ Hersoug, Monsen, Havik, and Høglend (2002) found that patients with lower pretreatment global functioning and more specific symptomatology developed worse early alliances (as rated by the therapist) than less symptomatic patients. Eaton, Abeles, and Gutfreund (1988) also found that higher pretreatment symptom severity predicted lower patient-rated alliance. On the other hand, some researchers have demonstrated that alliance ratings and pretreatment symptom severity are not significantly correlated (e.g., Connolly Gibbons et al., 2003; Gaston, Marmar, Thompson, \& Gallagher, 1988; Klein et al., 2003; Marmar et al., 1989). Thus, the association between patient symptom severity and the alliance remains uncertain.

The main goal for the current study was to assess the relation between pre- and early-treatment patient characteristics and the quality of the therapeutic relationship within controlled treatments for bulimia nervosa $(\mathrm{BN})$. Findings have shown that the alliance is predictive of both the process and outcome of treatment for BN. In studies derived from the same patient sample as the current study, Spangler, Baldwin, and Agras (2002) found that a quality therapeutic alliance was associated with increased patient engagement in treatment, and Loeb et al. (2002) found that early alliance predicted patient outcome in both CBT and IPT.

A secondary goal of the current study was to further assess the association between alliance and outcome in CBT and IPT for BN. Although the latter question was examined by Loeb et al. (2002), their alliance scores were based on independent assessor ratings. In the current study, we assessed patient-rated alliance for several reasons. First, the predictive validity of the alliance has been typically strongest when assessed by the patient (e.g., Barber et al., 1999; Castonguay \& Constantino, in press; Horvath \& Symonds, 1991; Tichenor \& Hill, 1989). Second, it is the patient's perception of the therapeutic relationship that is internalized and likely linked to therapeutic change (e.g., Safran \& Segal, 1990; Quintana \& Meara, 1990). Finally, previous studies have shown that, notwithstanding their own biases, patients are typically good assessors of the helpful aspects of the therapeutic relationship (e.g., Murphy, Cramer, \& Lillie, 1984).
The current study has several advantages over many previous examinations of patient characteristics and the alliance. First, it is based on a large sample, which allowed for the assessment of multiple variables. Second, its focus is on a carefully diagnosed, homogenous sample, which allows for disorder-specific information to be obtained. Third, this study involved two treatment modalities that approach the same clinical condition from different perspectives, allowing for the examination of factors that might be therapy specific. Moreover, these treatments were carried out in the context of a well-controlled therapy trial, with therapists demonstrating excellent protocol adherence in both treatment conditions (Loeb et al., 2002), thereby reducing the likelihood that within-group differences in treatment delivery are responsible for variance explained in the alliance (Connolly Gibbons et al., 2003).

Because previous research on the alliance in the treatment of eating disorders has been limited, a priori hypotheses were made only in areas that have received consistent support in the broader psychotherapy literature. ${ }^{2}$ Regarding our main goal of examining patient correlates of the alliance, we first predicted that patient expectation of improvement (assessed early in treatment) would be positively related to alliance development. Second, we hypothesized that pretreatment problems in interpersonal functioning would be negatively related to alliance quality. Because findings related to symptom severity and the alliance have been equivocal, no specific predictions were made regarding this association. However, because some evidence suggests a correlation between symptom severity and alliance quality, we included this comparison in our main analytic models to evaluate its significance in a bulimic population.

Regarding our secondary goal, we predicted that patient-rated alliance would be positively associated with outcome across both treatment conditions after accounting for pretreatment levels of symptomatology.

\section{Method}

Data for the current study derive from a multisite, randomized clinical trial comparing the effectiveness of CBT and IPT for BN (Agras, Walsh, Fairburn, Wilson, \& Kraemer, 2000). This trial involved two treatment sites (Stanford University and Columbia University) and a quality control center (Oxford University). Both treatments were conducted at each site, and there were no significant differences between treatments or sites with regard to treatment adequacy. For additional details regarding the research design, methods, and results, the reader is referred to Agras et al. (2000). Briefly, CBT was significantly more effective than IPT at posttreatment in terms of the percentage of patients (a) recovered, (b) remitted, and (c) meeting community norms for eating attitudes and behaviors. At 4-, 8-, and 12-month follow-up, however, there were no differences between the two treatments. In a separate report, Wilson, Fairburn, Agras, Walsh, and

\footnotetext{
${ }^{1}$ The authors defined naturalistic as involving an unselected sample of outpatients receiving treatment-as-usual across multiple outpatient clinics. The treatments were of varying lengths and provided by therapists with different levels of training and experience. Moreover, the treatments were uncontrolled and without adherence or competence ratings.

${ }^{2}$ It should also be noted that, because of the paucity of alliance research in the treatment of eating disorders, we had no specific predictions about differential associations between treatment conditions. Thus, we included treatment in our analytic models and report significant effects of treatment modality.
} 
Kraemer (2002) found that mediators of outcome included (a) reduction in dietary restraint at Weeks 4 and 6, (b) change in eating behavior selfefficacy, and (c) change in affective self-efficacy.

\section{Participants}

Patients. Two hundred twenty women (110 at each site) meeting Diagnostic and Statistical Manual of Mental Disorders (third edition, revised; DSM-III-R; American Psychiatric Association, 1987) criteria for $\mathrm{BN}$ were randomly assigned to treatment conditions. Exclusion criteria included (a) any severe physical or psychiatric condition that would interfere with therapy (e.g., psychosis), (b) current DSM-III-R-diagnosed anorexia nervosa, (c) currently engaging in any psychosocial treatment, (d) currently taking any psychotropic medication, (e) pregnancy, and (f) having received a previous adequate trial of CBT or IPT.

Patients were an average of 28.1 years old (SD // 7.2 years), and the duration of binge eating and purging averaged $11.4(S D \quad / / 7.5)$ and 9.8 $(S D$ // 6.8) years, respectively. Ethnicity of patients was as follows: Caucasian, 77\%; Hispanic, 11\%; African American, 6\%; Asian, 5\%; and American Indian, $1 \%$. The majority of the patients $(70.8 \%)$ were never married; $14.6 \%$ were married, $9.1 \%$ divorced, $5 \%$ divorced and remarried, and $0.5 \%$ widowed. With respect to comorbid psychopathology, $22 \%$ met criteria for current major depressive disorder (MDD) and $37 \%$ had a personality disorder. Lifetime rates of MDD and substance abuse or dependence were $53 \%$ and $23 \%$, respectively. CBT patients had significantly higher purge episodes and eating concerns at pretreatment than did IPT patients. Otherwise, the two groups were equivalent on pretreatment demographic variables and symptomatology. Several significant site differences were present at baseline. Stanford patients were, as a whole, older and more likely to have a lifetime diagnosis of substance abuse or dependence than those at Columbia. Patients at Columbia, relative to those at Stanford, had a longer duration of purging, were less likely to have a previous diagnosis of anorexia nervosa, had less concerns about eating and shape, and reported less global symptomatology.

Of the 220 patients randomized, $154(70 \%)$ completed treatment, 57 (26\%) dropped out of the study (31 in CBT and 26 in IPT), and 9 (4\%) were withdrawn for clinical reasons. Patients at Columbia dropped out at a significantly higher rate than those at Stanford. The current study included all patients who completed alliance measures at the assessments of interest.

Therapists. At each site, 4 therapists treated approximately equal numbers of patients in each of the two treatment conditions. All 8 therapists ( 7 doctoral-level psychologists and 1 psychiatrist) were experienced in the treatment of eating disorders and received extensive training in CBT and IPT for BN before the trial. To ensure standard protocol administration, therapists received weekly supervision from the primary site investigators as well as regular expert feedback from the quality control center.

\section{Treatments}

CBT and IPT are both manual-driven treatments that have received prior empirical support of efficacy for BN (see Agras, 1993). Both treatments involved 19 individual outpatient psychotherapy sessions conducted over the course of 20 weeks. Sessions were $50 \mathrm{~min}$ long and were delivered twice weekly for the first 2 weeks, weekly for the next 12 weeks, and biweekly for the remaining time.

CBT. Developed by Fairburn, Marcus, and Wilson (1993), CBT for $\mathrm{BN}$ is a directive approach that addresses the main symptomatic features of this psychiatric condition: (a) binge eating, (b) purging and other compensatory behaviors, and (c) excessive and often distorted body shape and weight concerns. In the first phase of treatment, therapists present a cognitive- behavioral model of $\mathrm{BN}$ and attempt to educate patients about the nature of their condition, the processes that maintain it, and its negative physiological consequences. Patients also monitor their food intake and compensatory behaviors. The second phase of treatment involves a continued focus on strategies to reduce dietary restraint and irregular eating. In addition, treatment focuses on cognitive and behavioral strategies for testing and challenging distorted thoughts and assumptions, decreasing avoidance of feared foods, and implementing adaptive coping responses to binge-eating triggers. Finally, the third stage of treatment centers on maintaining treatment gains and relapse prevention strategies.

IPT. Originally developed by Klerman, Weismann, Rounsaville, and Chevron (1984) for the treatment of depression, IPT was subsequently adapted for BN by Fairburn and colleagues (Fairburn, 1997; Fairburn, Jones, Peveler, Hope, \& O'Conner, 1993). IPT is an active but nondirective treatment that focuses on the interpersonal difficulties in the patient's life. Although therapists initially draw a connection between the patient's interpersonal difficulties and symptoms of $\mathrm{BN}$, this connection is only implied thereafter. Like CBT, IPT is composed of three phases. In Phase 1, an interpersonal model of therapy is presented and the patient is introduced to the four main realms of interpersonal difficulty: role disputes, role transitions, interpersonal deficits, and unresolved grief. The patient's eating disorder is placed within this interpersonal framework (e.g., a specific role dispute as a trigger for binge-eating). In Phase 2, the therapist maintains a nondirective stance in working with patients to implement adaptive interpersonal change in their lives. Phase 3 focuses on feelings about termination, a review of treatment gains, and strategies for coping with future interpersonal distress. Specific attention to eating patterns, compensatory behavior, or attitudes toward body shape and weight are proscribed in IPT. Moreover, this therapy involves neither self-monitoring nor specific behavioral instruction.

\section{Measures}

Purge Frequency Form (Agras et al., 2000). Patients recorded their 1-week purge frequency at baseline, at midtreatment (Session 12), and at posttreatment. Similar to Loeb et al. (2002), we selected posttreatment purge frequency as our main outcome variable in examining the association between the therapeutic alliance and treatment outcome. According to Wilson (1993), purge frequency recall poses fewer assessment liabilities than other indexes of eating pathology.

Eating Disorder Examination (EDE). The EDE (Cooper \& Fairburn, 1987; Fairburn \& Cooper, 1993) is a comprehensive, well-validated (e.g., Guest, 2000) structured interview that assesses the characteristic psychopathology of eating disorders. This interview, conducted at pre- and posttreatment, measures objective binge and purge frequency, concerns about shape, weight, and eating, and dietary restraint. The time frame for EDE assessment is the previous 28 days. The pretreatment administration of this measure was used as an index of symptom severity to examine its association with the therapeutic alliance.

Expectation of Improvement and Suitability of Treatment Form (Agras et al., 2000). After the first session, patients rated two one-item scales assessing expectation of improvement ("How successful do you think your treatment here will be?") and suitability of treatment ("How suitable do you think this treatment is for your problems?") using 15-point visual analogue scales ranging from 0 (not at all) to 15 (completely).

Inventory of Interpersonal Problems (IIP). The IIP (Horowitz, Rosenberg, Baer, Uren o,\& Villasen or, 1988) is a widely used self-report measure that assesses the extent of one's interpersonal difficulties. This instrument is composed of two sets of items (127 total): interpersonal inhibitions (e.g., "It is hard for me to trust other people") and interpersonal excesses (e.g., "I fight with other people too much"). Each item is rated on a 5-point scale ranging from 0 (not at all) to 4 (very much). The mean item rating was used as an index of overall interpersonal functioning. The IIP average score possesses good psychometric properties (Horowitz et al., 1988).

Helping Alliance Questionnaire (HAq). The HAq (Alexander \& Luborsky, 1986; Luborsky, 1984) is an 11-item self-report measure that assesses the quality of the therapeutic alliance from the patient's perspective. This instrument is based on Luborsky's (1976) conceptualization of 
Table 1

Intercorrelations of All Study Variables

\begin{tabular}{|c|c|c|c|c|c|c|c|c|c|}
\hline Variable & 1 & 2 & 3 & 4 & 5 & 6 & 7 & 8 & 9 \\
\hline 1. Baseline purge frequency & - & & & & & & & & \\
\hline 2. Midtreatment purge frequency (Session 12) & $.79 * * *$ & - & & & & & & & \\
\hline 3. Posttreatment purge frequency & $.76 * * *$ & $.91 * * *$ & - & & & & & & \\
\hline 4. Session $4 \mathrm{HAq}$ & .07 & $\geqslant .05$ & $\geqslant .09$ & - & & & & & \\
\hline 5. Session $12 \mathrm{HAq}$ & $\geqq .12$ & $\geqslant .27 * *$ & $\geqslant .23 * *$ & $.40 * * *$ & - & & & & \\
\hline 6. Session 1 expectancy factor & $.18 *$ & $.19 *$ & .13 & $.42 * * *$ & $.25 * *$ & - & & & \\
\hline 7. Baseline IIP average score & .13 & .03 & $\geqslant .00$ & $\geqq .16^{*}$ & $\geqslant .15$ & $\geqslant .05$ & - & & \\
\hline 8. Baseline EDE symptom composite & $.50 * * *$ & $.38 * * *$ & $.27 * *$ & $\geqslant .03$ & $\geqslant .12$ & .09 & $.47 * * *$ & - & \\
\hline 9. Prior symptom change & .00 & $.61 * * *$ & $.49 * * *$ & $\geqslant 15$ & $\geqslant 27^{* *}$ & .09 & $\geqslant .06$ & $\geqslant .01$ & - \\
\hline
\end{tabular}

Note. Baseline, midtreatment, and posttreatment purge frequency // patients' self-reported 1-week purge frequency; HAq // Helping Alliance Questionnaire; expectancy factor // summed $z$ scores for the expectation of improvement and suitability of treatment ratings; IIP // Inventory of Interpersonal Problems; EDE symptom composite // summed $z$ scores for the six subscales of the Eating Disorder Examination; prior symptom change // unstandardized residual change on objective purge frequency from baseline to Session 12.

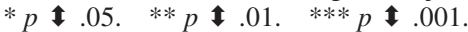

the alliance that reflects the patient's perception of receiving therapistoffered helpfulness and supportiveness (e.g., "I believe that my therapist is helping me") and the patient's experience of working collaboratively with his or her therapist on agreed-on treatment goals (e.g., "I feel I am working together with the therapist in a joint effort"). Patients rate each item on a 6-point scale (3 // I strongly feel it is true, $\geqslant 3$ // I strongly feel it is not true). Because these values actually represent a recoding of the printed scale that ranges from 1 to 6 , there is no zero point. For the current study, the total score for the HAq was used as the index of alliance quality. The HAq possesses good psychometric properties and has been shown to correlate with treatment outcome (e.g., Alexander \& Luborsky, 1986; Luborsky, McLellan, Woody, O'Brien, \& Auerbach, 1985).

\section{Procedure}

After being recruited by advertisements or referrals from local clinics, potential participants were initially screened by telephone for study eligibility. Participants who were not ruled out at the initial screening were scheduled for an in-person, baseline clinical assessment with a trained research assistant. After obtaining informed consent, research assistants administered the EDE to assess for eating disorder symptomatology and the Structured Clinical Interview for the DSM-III-R (SCID; Spitzer, Williams, Gibbon, \& First, 1989) to assess for general psychopathology. If eligible for the study, participants also completed a baseline battery of self-report measures, including the 1-week purge frequency form, the IIP, and several other instruments not related to the current study. Participants rated their expectation of improvement and the suitability of treatment after Session 1. The HAq was administered after Sessions 4 and 12. ${ }^{3}$ At posttreatment, research assistants again administered the EDE. Patients also completed the 1-week purge frequency form in addition to other instruments not related to this study.

\section{Results}

For all study variables, the intercorrelations are presented in Table 1. Because of missing data, sample sizes vary across analyses. We report the sample size and descriptive statistics for each analysis. An alpha level of .05 was chosen a priori.

\section{Patient Characteristics and the Early Alliance}

First, we assessed the association between pre- and earlytreatment patient characteristics and patient-therapist alliance at early treatment (i.e., Session 4). Because the one-item ratings for expectation of improvement and suitability of treatment were collinear $(r / / .53, p \mathbf{t} .01)$, these measures were standardized by means of $z$-score transformation and submitted to a principal-axis factor analysis with oblimin rotation. As might be expected with these conceptually related constructs, one factor was extracted (eigenvalue // 1.53), which explained $76 \%$ of the variance. The factor loading for each measure was .73. Consequently, the $z$ scores for the expectancy and suitability measures were summed to produce an index of early treatment expectancies.

The IIP mean item rating was used as the pretreatment measure of interpersonal problems. To assess baseline pretreatment symptom severity, we computed a composite score by standardizing and summing the $z$ scores for the six EDE subscales (Objective Binge Frequency, Objective Purge Frequency, Shape Concerns, Weight Concerns, Eating Concerns, and Dietary Restraint). This composite measure had high internal consistency (Cronbach's $\bullet$ // .71) and represents the global spectrum of eating disorder symptomatology.

We conducted preliminary analyses to assess for associations between patient demographic characteristics and the alliance. Age, ethnicity (coded as Caucasian vs. minority), and marital status (coded as currently married vs. currently not married) were not significantly associated with early or middle alliance when analyzed across treatments groups (Pearson $r$ s range $/ / \geqslant .05$ to $\geqslant .01$ ) or by treatment group (Pearson $r$ s range $/ / \geqslant .13$ to .21 in CBT; $\geqq .14$ to .05 in IPT). Thus, no demographic variables were included as covariates in the main analytic models.

To assess patient correlates of early alliance, we conducted a hierarchical linear regression ( $n / /$ 186) including treatment and treatment site as covariates in Step 1; the expectancy factor ( $M / /$ $.06, S D / / 1.70)$, IIP average score $(M / / 1.60, S D / / .56)$, and EDE symptom composite $(M / / .04, S D / / 4.10)$ as predictors in Step 2; and all Treatment /// Predictor interactions in Step 3 (to examine whether any predictors were treatment specific). The dependent variable was the Session 4 HAq total score $(M / / 18.28$, $S D$ // 7.07). The two binary variables (treatment and treatment

\footnotetext{
${ }^{3}$ A late treatment alliance assessment occurred after the final session. Because this essentially reflects a posttreatment assessment likely confounded by perceived improvement and termination issues, we did not include late alliance as a predictor of posttreatment outcome.
} 
Table 2

Summary of Hierarchical Multiple Regression Analysis Predicting Early Alliance (HAq Session 4) From Patient Characteristics (n // 186)

\begin{tabular}{|c|c|c|}
\hline Variable & Part $r$ & $\mathrm{~N}_{\mathrm{L}}$ \\
\hline Step 1 & \multicolumn{2}{|c|}{$R^{2} / / .05, F(2,183) / / 4.27^{*}$} \\
\hline Treatment site & .19 & $.19 * *$ \\
\hline Treatment & $\geqq .08$ & $\geqslant .08$ \\
\hline Step 2 & \multicolumn{2}{|c|}{ ৫ $R^{2} / / .20, \Theta F(3,180) / / 15.38 * * *$} \\
\hline Treatment site & .09 & .09 \\
\hline Treatment & $\geqq 16$ & $\geqq 16^{*}$ \\
\hline Expectancy factor & .42 & $.43 * * *$ \\
\hline IIP average score & $\geqq .11$ & $\geqq .13$ \\
\hline EDE symptom composite & .02 & .02 \\
\hline Step 3 & \multicolumn{2}{|c|}{ @ $R^{2} / / .01$, 田 $F(3,177) / / .77$} \\
\hline Treatment site & .09 & .09 \\
\hline Treatment & $\geqq 16$ & $\geqq .17 *$ \\
\hline Expectancy factor & .43 & $.45 * * *$ \\
\hline IIP average score & $\geqslant .11$ & $\geqslant .13$ \\
\hline EDE symptom composite & .01 & .01 \\
\hline \multicolumn{3}{|l|}{ Expectancy Factor /// } \\
\hline Treatment & .09 & .09 \\
\hline IIP /// Treatment & $\geqq .01$ & $\geqq .01$ \\
\hline \multicolumn{3}{|l|}{ EDE Symptom Composite } \\
\hline /// Treatment & .04 & .04 \\
\hline
\end{tabular}

Note. HAq // Helping Alliance Questionnaire; expectancy factor // sum of $z$ scores for the expectation of improvement and suitability of treatment ratings; IIP // Inventory of Interpersonal Problems; EDE symptom composite // sum of the $z$ scores for the six subscales of the Eating Disorder Examination.

$* p \$ .05 . * * p \$ .01 . * * * p \$ .001$.

site) were coded — 0.5: CBT and Columbia (-0.5) and IPT and Stanford (0.5). The remaining ordinal variables were all centered at their means. See Table 2 for results. Treatment group was significantly associated with the alliance at Session 4; patients in CBT reported better early alliances than those in IPT. In addition, patients with higher early treatment expectations of improvement formed better early alliances with their therapists than those with lower expectations of improvement. ${ }^{4}$

\section{Patient Characteristics and the Middle Alliance}

Second, we assessed the association between pre- and earlytreatment patient characteristics and patient-therapist alliance at middle treatment (i.e., Session 12). To do so, we followed an approach similar to that for early alliance. However, because a previous study (Wilson et al., 1999) that assessed processes of change in the treatment of $\mathrm{BN}$ showed that symptom change through Session 12 predicted the Session 12 alliance score, we included prior symptom change as a covariate in this model. This design helps to clarify whether a given variable has a direct association with the alliance as opposed to exerting its influence through its relation with symptomatic improvement (Connolly Gibbons et al., 2003). To measure symptom change from baseline to the Session 12 alliance assessment, we computed a change score on the objective measure of purge frequency. To do this, we conducted a linear regression with Session 12 purge frequency as the dependent variable and baseline purge frequency as the independent variable, which produces a new variable: an unstandardized residual reflecting purge frequency at Session 12 not ac- counted for by purge frequency at baseline. Although this symptom variable reflects only one aspect of eating disorder pathology, a Pearson product-moment correlation revealed a significant positive association between baseline purge frequency and baseline EDE symptom composite $(r / / .50, p \boldsymbol{\uparrow} .01)$, suggesting that purge frequency is a valid representation of prior symptom change. It was not possible to use the EDE composite as a measure of symptom change because only self-report measures were administered during treatment.

We conducted a hierarchical linear regression ( $n$ // 150) including treatment, treatment site, and prior symptom change $(M / /$ $\geqq 10, S D / / 8.27)$ as covariates in Step 1; the expectancy factor $(M / / .17, S D / / 1.67)$, the IIP average score $(M / / 1.54, S D / /$ $.55)$, and the EDE symptom composite $(M / / \geqslant .48, S D / / 4.10)$ as predictors in Step 2; and all Treatment /// Predictor interactions in Step 3. The dependent variable was the Session $12 \mathrm{HAq}$ total score ( $M$ // 21.61, SD // 7.56). The binary variables were coded [ 0.5 and the ordinal variables were centered at their means. Prior symptom change (part $r / / \geqslant .27, \mathrm{~N}_{\mathrm{L}} / / \geqslant .29, p \downarrow .01$ ), expectation of improvement (part $r / /$.32, $N_{\mathrm{L}} / / \quad .33, p \quad .01$ ), and the Treatment /// IIP interaction (part $r / / \geqslant .15, \mathrm{~N}_{\mathrm{L} / / \geqslant .17, p} \mathbf{t} .05$ ) were significantly associated with middle-alliance quality (overall model $R^{2} / / .24$ ). To clarify the interaction and to assess treatmentspecific correlates of middle alliance, we conducted two similar regressions (i.e., stratified by treatment group). See Table 3 for the results of these analyses. In CBT, expectation of improvement was positively associated with middle alliance when accounting for symptom change from baseline to Session 12. Symptom severity was negatively associated with middle alliance. There was no association between interpersonal problems and middle alliance in CBT.

In IPT, prior symptom change was associated with middle alliance; patients who reported greater change in purge frequency from baseline to Session 12 reported better alliances at Session 12. Also in IPT, expectation of improvement was positively associated with middle alliance, whereas the degree of pretreatment interpersonal problems was negatively associated with middle alliance, after accounting for prior symptom change. There was no association between baseline symptom severity and middle alliance.

\section{Alliance and Outcome}

Finally, we examined the association between patient-rated alliance (at early and middle treatment) and treatment outcome (i.e., purge frequency over the prior week as assessed at posttreatment).

\footnotetext{
${ }^{4}$ In its assessment of therapist-offered helpfulness, one item of the HAq (i.e., "I can already see that I will eventually work out the problems I came to treatment for") is conceptually similar to the general expectation of improvement factor used in the prediction of the alliance (i.e., both involve prognostication of how helpful treatment will be). Because of this potential confound, we recalculated the total score for the Session 4 HAq dropping the above item. We then conducted the same hierarchical regression analysis with the new Session $4 \mathrm{HAq}$ variable and found a nearly identical coefficient and the same significance level for the expectancy factor. We conducted the same check for the Session $12 \mathrm{HAq}$ analyses reported here and also found a consistent pattern of findings. Thus, we have reported findings for the full version of the HAq in both the early- and middlealliance analyses.
} 
Table 3

Summary of Hierarchical Multiple Regression Analyses Predicting Middle Alliance (HAq Session 12) From Patient Characteristics, Including Prior Symptom Change as a Covariate (Stratified by Treatment Group)

\begin{tabular}{|c|c|c|c|c|}
\hline \multirow[b]{2}{*}{ Variable } & \multicolumn{2}{|c|}{$\mathrm{CBT}(n / / 73)$} & \multicolumn{2}{|c|}{ IPT $(n / / 77)$} \\
\hline & Part $r$ & $\mathrm{~N}_{\mathrm{L}}$ & Part $r$ & $\mathrm{~N}_{\mathrm{L}}$ \\
\hline Step 1 & \multicolumn{2}{|c|}{$R^{2} / / .03, F(2,70) / / 1.10$} & \multicolumn{2}{|c|}{$R^{2} / / .15, F(2,74) / / 6.38^{* *}$} \\
\hline Treatment site & .05 & .06 & $\geqslant .07$ & $\geqq .07$ \\
\hline Prior symptom change & $\geqq .16$ & $\geqslant .16$ & $\geqslant .34$ & $\geqslant .36^{* *}$ \\
\hline Step 2 & \multicolumn{2}{|c|}{$\mathbb{Q} R^{2} / / .21, \mathbb{Q} F(3,67) / / 6.12^{* *}$} & \multicolumn{2}{|c|}{$\mathbb{Q} R^{2} / / .11, \mathbb{F}(3,71) / / 3.52 *$} \\
\hline Treatment site & $\geqq .04$ & $\geqslant .04$ & $\geqslant .11$ & $\geqq .11$ \\
\hline Prior symptom change & $\geqslant .12$ & $\geqslant .12$ & $\geqslant .38$ & $\geqslant .41 * * *$ \\
\hline Expectancy factor & .39 & $.41 * * *$ & .25 & $.26^{*}$ \\
\hline IIP average score & .08 & .09 & $\geqslant .23$ & $\geqslant .25^{*}$ \\
\hline \multicolumn{5}{|l|}{ EDE symptom } \\
\hline composite & $\geqslant .22$ & $\geqslant .25^{*}$ & .00 & .00 \\
\hline
\end{tabular}

Note. HAq // Helping Alliance Questionnaire; CBT // cognitive- behavioral therapy; IPT // interpersonal therapy; prior symptom change // unstandardized residual change on objective purge frequency from baseline to Session 12; expectancy factor // sum of the $z$ scores for the expectation of improvement and suitability of treatment ratings; IIP // Inventory of Interpersonal Problems; EDE symptom composite // sum of the $z$ scores for the six subscales of the Eating Disorder Examination.

$* p$ I $.05 . \quad * * p \mathbf{t} .01 . \quad * * * p \mathbf{t} .001$.

Because of the known treatment effect on posttreatment outcome (Agras et al., 2000), we tested the alliance- outcome association separately for CBT and IPT using hierarchical linear regression models with baseline purge frequency as a covariate. See Table 4 for the means and standard deviations of the variables related to the following alliance- outcome analyses. In CBT, both early alliance (part $r / / \geqslant .38, \mathrm{~N}_{\mathrm{L}} / / \geqslant .38, p \quad .01$ ) and middle alliance (part $r / / \geqslant .27, \mathrm{~N}_{\mathrm{L}} / / \geqslant .27, p \quad .05$ ) were significantly associated with posttreatment purge frequency when accounting for baseline purge frequency (overall model $R^{2} / / .33$ and .30 , respectively). That is, better alliance quality was related to less frequent purging.

In IPT, middle alliance (part $r / / \geqslant .17, N_{\mathrm{L}} / / \geqslant .17, p \quad .05$ ) was significantly associated with posttreatment purge frequency when accounting for baseline purge frequency (overall model $R^{2} / / .69$ ); however, there was no association between early alliance (part $r$ //

Table 4

Means and Standard Deviations of Variables Related to Alliance-Outcome Analyses (Stratified by Treatment Group)

\begin{tabular}{|c|c|c|c|c|}
\hline \multirow[b]{2}{*}{ Variable } & \multicolumn{2}{|c|}{ CBT } & \multicolumn{2}{|c|}{ IPT } \\
\hline & $M$ & $S D$ & $M$ & $S D$ \\
\hline \multicolumn{5}{|l|}{ Early-alliance analyses ${ }^{\mathrm{a}}$} \\
\hline Session $4 \mathrm{HAq}$ & 18.42 & 7.57 & 18.11 & 6.96 \\
\hline Baseline purge frequency & 10.89 & 8.90 & 16.34 & 18.31 \\
\hline Posttreatment purge frequency & 2.48 & 4.63 & 7.91 & 13.24 \\
\hline \multicolumn{5}{|l|}{ Middle-alliance analyses ${ }^{\mathrm{b}}$} \\
\hline Session $12 \mathrm{HAq}$ & 21.13 & 9.01 & 21.86 & 7.09 \\
\hline Baseline purge frequency & 10.47 & 8.88 & 15.87 & 18.22 \\
\hline Posttreatment purge frequency & 2.24 & 4.48 & 7.74 & 13.09 \\
\hline
\end{tabular}

Note. $\mathrm{CBT} / /$ cognitive- behavioral therapy; IPT // interpersonal therapy; HAq // Helping Alliance Questionnaire; baseline and posttreatment purge frequency // patients' self-reported 1-week purge frequency.

${ }^{\mathrm{a}} \mathrm{CBT} n / / 71 ; \operatorname{IPT} n / / 76 . \quad{ }^{\mathrm{b}} \mathrm{CBT} n / / 72 ; \operatorname{IPT} n / / 74$. $\geqq .09, N_{L} / / \geqslant .09, p / / .18$ ) and posttreatment purge frequency when accounting for baseline purge frequency (overall model $₹ / / .66$ ).

\section{Discussion}

The primary goal of the current study was to examine patient characteristics and their association with the therapeutic alliance in diverse psychotherapies for BN. The main findings are as follows: (a) Patient early expectation of improvement was positively related to both early- and middle-alliance quality in both CBT and IPT for $\mathrm{BN}$, (b) baseline interpersonal problems were associated with poorer middle-alliance quality in IPT only, and (c) baseline symptom severity was negatively related to middle-alliance quality in CBT only. In addition, patients in CBT reported better early alliances than those in IPT. Related to our secondary aim of the current study, better early alliance was associated with patient improvement in both CBT and IPT. Middle alliance was positively correlated with patient improvement in CBT but not IPT.

As hypothesized, patient expectation of improvement was associated with early- and middle-alliance quality in both CBT and IPT. Although previous studies have revealed a positive association between expectancies and treatment outcome (see Arnkoff, Glass, \& Shapiro, 2002, for a review), few have examined the relation between expectancies and psychotherapy process (Connolly Gibbons et al., 2003). Furthermore, even fewer studies have examined the impact of expectancies on process as a function of treatment type (Glass, Arnkoff, \& Shapiro, 2001). In the current study, patients who believed that treatment would help them reduce their eating difficulties formed better alliances with their therapists in both CBT and IPT than did those who had less belief that therapy would help. Moreover, this relationship held when accounting for prior symptomatic improvement. Such results are consistent with previous findings (e.g., Connolly Gibbons et al., 2003) as well as with goal and expectancy theories that suggest that people will be more motivated to engage constructively in a task if they 
believe the desired outcome can be attained (e.g., Carver \& Scheier, 1998; Meyer et al., 2002). Such engagement may be akin to the collaborative working bond that comprises a quality alliance and may be an important ingredient of clinical improvement.

Because of the correlational nature of much of the research on psychotherapy expectancies (including the current study), it is premature to conclude that expectation of improvement is a causal factor in alliance development and treatment outcome (Glass et al., 2001). However, the consistent and moderately strong associations in the current study suggest that therapists should make a concerted effort early in treatment to assess, discuss explicitly, and foster patient expectations of improvement in the service of building better relationships with their patients (e.g., Kirsch, 1990). Such interventions may take the form of (a) explicit hope-inspiring statements (e.g., "It makes sense that you sought this type of help for your difficulties"; "Your problems are exactly the type for which this therapy can be of help"), (b) providing a thorough rationale of the treatment approach to convey to patients that others have similar difficulties and that treatments have been developed (and tested, if applicable) to address these difficulties, and (c) nontechnical review of treatment research specific to patients' difficulties (e.g., provision of typical success rates or time-to-response estimates; Arnkoff et al., 2002; Glass et al., 2001). Although both CBT and IPT often include strategies to facilitate positive expectancies and engagement in treatment, such strategies are often general and of secondary focus (Meyer et al., 2002). It is possible that paying more central and specific attention to increasing expectations of improvement may improve both the therapeutic alliance and treatment outcome. It will be impor tant for future studies to implement designs (e.g., placebo control) to isolate more effectively specific versus expectancy-placebo effects in psychotherapy.

Unlike treatment expectancies, the associations between baseline interpersonal problems and alliance as well as baseline symptom severity and alliance were specific to the time the alliance was assessed and to treatment type. In IPT only, baseline interpersonal problems were significantly associated with the middle, but not early, alliance in the hypothesized direction; patients with greater interpersonal difficulties reported worse midtreatment alliances with their therapists. In CBT only, patients with more severe baseline symptoms reported worse alliances with their therapists at Session 12 but not Session 4.

Thus, neither degree of baseline interpersonal problems nor symptom severity was significantly associated with the formation of a good early alliance in either treatment. In both treatments, the early focus is on placing eating difficulties within a particular theoretical framework linked to the treatment strategies. In this largely psychoeducational phase, it may be that interpersonal problems and symptom severity pose less of a problem for bond development and agreement on tasks and goals. Other factors, such as expectation of improvement, may be more crucial at this time.

The differential findings for the middle alliance, however, may be associated with the different demands that CBT and IPT place on the patient (Bordin, 1979). That is, patients with the least adaptive baseline scores on the target symptoms of their respective treatments (i.e., eating disorder symptoms in CBT and interpersonal problems in IPT) had poorer midtreatment relationships with their therapists. It is possible that the interpersonal focus in IPT pulls for greater enactment of interpersonal issues and relational problems that were present before treatment. By the middle stage of therapy, interpersonal disputes, transitions, deficits, and grief are the main therapeutic foci in IPT, and more severe deficits in these realms may make it more difficult to further establish or to maintain a good patient-therapist relationship. There is supporting evidence that maladaptive interpersonal or attachment histories have a negative impact on the patient-therapist process in dynamic or interpersonally oriented therapies (e.g., Hilliard, Henry, \& Strupp, 2000). In the more directive and structured CBT, however, interpersonal issues may be less likely to surface and thus less likely to have an adverse effect on the alliance. For example, patients in CBT, despite their interpersonal deficits, may be better able to agree with their therapists on the explicit, concrete, symptom-focused tasks and goals of therapy than those in the less structured IPT condition.

It may be that the specific focus on eating disorder symptoms in CBT is a strength in fostering an early alliance, irrespective of symptom severity, but may be a liability later in treatment for those who remain highly symptomatic. In a separate study on CBT for $\mathrm{BN}$, Wilson et al. (1999) found that high baseline severity of binge eating and purging was a negative predictor of outcome. For these more severely disturbed patients, it may be more difficult to remain engaged in a collaborative, affiliative relationship with their therapists when the focus of treatment is so squarely on symptom resolution. For example, these patients may have more difficulty successfully challenging the distorted nature of their thinking (a cardinal feature of CBT) than those with less severe baseline symptoms (Rude \& Rehm, 1991). In response, they may experience a sense of failure and may become disenchanted with such cognitive strategies and perhaps the therapist's reliance on them. Furthermore, the repeated use of these strategies in strained interpersonal contexts may create an alliance rupture (Castonguay, Goldfried, Wiser, Raue, \& Hayes, 1996; Castonguay et al., 2004). Perhaps in the less directive IPT condition, ruptures of this type are less frequent, even when patients present with severe baseline symptoms.

Treatment group was also significantly associated with the early alliance; patients in CBT reported better Session 4 alliances than those in IPT. This finding is consistent with Raue et al. (1993), who found that observer-rated alliance was greater in CBT than a rival, more interpersonally oriented treatment (i.e., psychodynamic-interpersonal therapy). Regarding the current treatments, it is possible that CBT has more face validity than IPT early in therapy. With CBT's explicit focus on eating patterns and symptoms, patients in this treatment may have an easier time agreeing on the tasks and goals of treatment and forging a solid bond with their therapist than those in IPT. Later in treatment, however, this initial face validity may have less bearing on the quality of the alliance.

In addition to examining patient correlates of the alliance, we examined the association between patient-rated alliance and outcome. In CBT, both early and middle alliance were positively correlated with outcome when accounting for baseline purge frequency. In IPT, middle, but not early, alliance was associated with outcome when accounting for baseline symptom level. These findings are consistent with the general psychotherapy literature suggesting that the alliance, as rated from the patient's perspective, is a relatively robust predictor of outcome across various treatments for various psychological conditions (e.g., Constantino et al., 2002; Horvath \& Bedi, 2002). Furthermore, the findings complement those of Loeb et al. (2002) in suggesting that the thera- 
peutic alliance is an important predictor of outcome in the treatment of BN. More specifically, however, early alliance was not associated with outcome in IPT. It could be that earlier in IPT, when the focus is on placing eating difficulties in an interpersonal context, the patient-therapist collaborative bond is less significant for outcome. However, in the middle of therapy, when interpersonal themes have been identified and are being addressed, the negotiation of the patient-therapist relationship may be an important ingredient of change.

Several limitations characterize the current study. First, with the exception of the symptom composite derived from the EDE, all measures were derived from patient ratings. Consequently, the shared method variance could spuriously increase associations. Second, we were only able to control for one aspect of eating disorder pathology (i.e., purge frequency) when examining the association between patient characteristics and the middle alliance accounting for prior symptom change. It could be that reductions in other facets of eating problems by middle treatment could also contribute to alliance quality. That said, baseline purge frequency in this sample was significantly correlated with our baseline symptom composite measure, suggesting that it was a valid representation of symptom change. Third, we used two one-item, face valid measures assessing expectation of improvement and credibility of treatment for which no psychometric data exist. Although we found moderately strong associations between early treatment expectancies and the alliance, even stronger effects might have been observed with an expectancy measure with established psychometric properties (e.g., Devilly \& Borkovec, 2000). Finally, all findings in this study should be interpreted with caution in that they (a) do not imply causation and (b) may have been affected by errors associated with multiple assessments. However, we attempted to combat this issue by limiting the number of comparisons to those variables with prior theoretical and empirical support. Moreover, this study had multiple strengths over prior investigations of alliance predictors. These included a large sample from a well-controlled randomized clinicaltrial, a carefully diagnosed homogenous sample, and diverse therapies conducted by expert clinicians.

The current findings suggest that several patient characteristics play a role in the development of quality alliances, with some characteristics specific to the type of therapy. These markers for potential alliance strains can inform the clinician's approach to different patients. That is, knowing that a given patient is at risk for relational problems with his or her therapist may allow the therapist to adapt treatment strategies, including a more explicit focus on fostering a collaborative therapeutic bond (e.g., Safran \& Segal, 1990). The current findings add to a second generation of alliance research that has begun to illuminate factors related to alliance development (Safran et al., 2002).

\section{References}

Agras, W. S. (1993). Short-term psychological treatments for binge eating In C. G. Fairburn \& G. T. Wilson (Eds.), Binge eating: Nature, assessment, and treatment (pp. 270 -286). New York: Guilford Press.

Agras, W. S., Walsh, T. B., Fairburn, C. G., Wilson, G. T., \& Kraemer, H. C. (2000). A multicenter comparison of cognitive-behavioral therapy and interpersonal psychotherapy for bulimia nervosa. Archives of General Psychiatry, 57, $459-466$.

Alexander, L. B., \& Luborsky, L. (1986). The Penn Helping Alliance Scales. In L. S. Greenberg \& W. M. Pinsoff (Eds.), The psychothera- peutic process: A research handbook (pp. 325-366). New York: Guilford Press.

American Psychiatric Association. (1987). Diagnostic and statistical man ual of mental disorders (3rd ed., rev.). Washington, DC: Author.

Arnkoff, D. B., Glass, C. R., \& Shapiro, S. J. (2002). Expectations and preferences. In J. C. Norcross (Ed.), Psychotherapy relationships that work: Therapists contributions and responsiveness to patients (pp. 325346). New York: Oxford University Press.

Austin, J. T., \& Vancouver, J. B. (1996). Goal constructs in psychology: Structure, process, and content. Psychological Bulletin, 120, $338-375$

Barber, J. P., Luborsky, L., Crits-Christoph, P., Thase, M. E., Weiss, R., Frank, A., et al. (1999). Therapeutic alliance as a predictor of outcome in treatment of cocaine dependence. Psychotherapy Research, 9, 54 -73.

Bordin, E. S. (1979). The generalizability of the psychoanalytic concept of the working alliance. Psychotherapy, 16, 252-260.

Carver, C. S., \& Scheier, M. (1998). On the self-regulation of behavior New York: Cambridge University Press.

Castonguay, L. G., \& Constantino, M. J. (in press). Engagement in psychotherapy: Factors contributing to the facilitation, demise, and restoration of the working alliance. In D. Castro-Blanco (Ed.), Treatment engagement with adolescents. Washington, DC: American Psychological Association.

Castonguay, L. G., Goldfried, M. R., Wiser, S., Raue, P. J., \& Hayes, A. M. (1996). Predicting the effect of cognitive therapy for depression: A study of unique and common factors. Journal of Consulting and Clinical Psychology, 64, 497-504.

Castonguay, L. G., Schut, A. J., Aikins, D., Constantino, M. J., Laurenceau, J. P., Bologh, L., \& Burns, D. D. (2004). Repairing alliance ruptures in cognitive therapy: A preliminary investigation of an integrative therapy for depression. Journal of Psychotherapy Integration, 14, $4-20$.

Connolly Gibbons, M. B., Crits-Christoph, P., de la Cruz, C., Barber, J. P., Siqueland, L., \& Gladis, M. (2003). Pretreatment expectations, interpersonal functioning, and symptoms in the prediction of the therapeutic alliance across supportive- expressive psychotherapy and cognitive therapy. Psychotherapy Research, 13, $59-76$.

Constantino, M. J. (2000). Interpersonal process in psychotherapy through the lens of the structural analysis of social behavior. Applied and Preventive Psychology, 9, 153-172.

Constantino, M. J., Castonguay, L. G., \& Schut, A. J. (2002). The working alliance: A flagship for the scientist-practitioner model in psychotherapy. In G. S. Tryon (Ed.), Counseling based on process research: Applying what we know (pp. 81-131). Boston: Allyn \& Bacon.

Cooper, Z., \& Fairburn, C. G. (1987). The Eating Disorders Examination: A semi-structured interview for the assessment of the specific psychopathology of eating disorders. International Journal of Eating Disorders, $6,1-8$

Devilly, G. J., \& Borkovec, T. D. (2000). Psychometric properties of the credibility/expectancy questionnaire. Journal of Behavior Therapy and Experimental Psychiatry, 31, 73-86.

Eaton, T. T., Abeles, N., \& Gutfreund, M. J. (1988). Therapeutic alliance and outcome: Impact of treatment length and pretreatment symptomatology. Psychotherapy, 25, 536-542.

Fairburn, C. G. (1997). Interpersonal therapy for bulimia nervosa. In D. M. Garner \& P. E. Garfinkel (Eds.), Handbook of treatment for eating disorders (pp. 67-93). New York: Guilford Press.

Fairburn, C. G., \& Cooper, Z. (1993). The Eating Disorder Examination (12th ed.). In C. G. Fairburn \& G. T. Wilson (Eds.), Binge eating: Nature, assessment, and treatment (pp. 317-360). New York: Guilford Press.

Fairburn, C. G., Jones, R., Peveler, R. C., Hope, R. A., \& O’Conner, M. (1993). Psychotherapy and bulimia nervosa: Longer-term effects of interpersonal psychotherapy, behavior therapy, and cognitive behavior therapy. Archives of General Psychiatry, 50, $419-428$. 
Fairburn, C. G., Marcus, M. D., \& Wilson, G. T. (1993). Cognitive behavior therapy for binge eating and bulimia nervosa: A treatment manual. In C. G. Fairburn \& G. T. Wilson (Eds.), Binge eating: Nature, assessment, and treatment (pp. 361-404). New York: Guilford Press.

Gaston, L., Marmar, C. R., Thompson, L. W., \& Gallagher, D. (1988). Relation of patient pretreatment characteristics to the therapeutic alliance in diverse psychotherapies. Journal of Consulting and Clinical Psychology, 56, 483- 489.

Glass, C. R., Arnkoff, D. B., \& Shapiro, S. J. (2001). Expectations and preferences. Psychotherapy, 38, 455- 461.

Guest, T. (2000). Using the Eating Disorder Examination in the assessment of bulimia and anorexia nervosa: Issues of reliability and validity. Social Work in Health Care, 31, 71-83.

Hersoug, A. G., Monsen, J. T., Havik, O. E., \& Høglend, P. (2002). Quality of early working alliance in psychotherapy: Diagnoses, relationship and intrapsychic variables as predictors. Psychotherapy and Psychosomatics, $71,18-27$

Hilliard, R. B., Henry, W. P., \& Strupp, H. H. (2000). An interpersonal model of psychotherapy: Linking patient and therapist developmental history, therapeutic process, and types of outcome. Journal of Consulting and Clinical Psychology, 68, 125-133.

Horowitz, L., M., Rosenberg, S. E., Baer, B. A., Uren o, G., \& Villasen or, V. S. (1988). Inventory of Interpersonal Problems: Psychometric properties and clinical applications. Journal of Consulting and Clinical Psychology, 56, 885-892.

Horvath, A. O. (1994). Empirical validation of Bordin's pantheoretical model of the alliance: The Working Alliance Inventory perspective. In A. O. Horvath \& L. S. Greenberg (Eds.), The working alliance: Theory, research and practice (pp. $109-128)$. New York: Wiley.

Horvath, A. O., \& Bedi, R. P. (2002). The alliance. In J. C. Norcross (Ed.), Psychotherapy relationships thatwork: Therapists contributions and responsiveness to patients (pp. 37-69). New York: Oxford University Press

Horvath, A. O., \& Symonds, D. B. (1991). Relationship between working alliance and outcome in psychotherapy: A meta-analysis. Journal of Counseling Psychology, 38, $139-149$.

Joyce, A. S., Ogrodniczuk, J. S., Piper, W. E., \& McCallum, M. (2003). The alliance as mediator of expectancy effects in short-term individual therapy. Journal of Consulting and Clinical Psychology, 71, 672- 679.

Joyce, A. S., \& Piper, W. E. (1998). Expectancy, the therapeutic alliance, and treatment outcome in short-term individual psychotherapy. Journal of Psychotherapy Practice and Research, 7, 236 -248.

Kirsch, I. (1990). Changing expectations: A key to effective psychotherapy. Pacific Grove, CA: Brooks/Cole.

Klein, D. N., Schwartz, J. E., Santiago, N. J., Vivian, D., Vocisano, C., Castonguay, L. G., et al. (2003). Therapeutic alliance in depression treatment: Controlling for prior change and patient characteristics. Journal of Consulting and Clinical Psychology, 71, 997-1006.

Klerman, G. L., Weismann, M. M., Rounsaville, B. J., \& Chevron, E. S. (1984). Interpersonal psychotherapy for depression. New York: Basic Books.

Loeb, K. L., Wilson, G. T., Pratt, E. M., Hayaki, J., Labouvie, E., Walsh, B. T., et al. (2002). Therapeutic alliance and treatment adherence in two interventions for bulimia nervosa: A study of process and outcome. Manuscript submitted for publication.

Luborsky, L. (1976). Helping alliances in psychotherapy. In J. L. Cleghorn (Ed.), Successful psychotherapy (pp. 92-116). New York: Brunner/ Mazel.

Luborsky, L. (1984). Principles of psychoanalytic psychotherapy: A manual for supportive-expressive treatment. New York: Basic Books.

Luborsky, L., McLellan, A. T., Woody, G. E., O’Brien, C. P., \& Auerbach, A. (1985). Therapist success and its determinants. Archives of General Psychiatry, 42, 602-611.
Marmar, C. R., Weiss, D. S., \& Gaston, L. (1989). Toward the validation of the California Therapeutic Alliance Rating System. Psychological Assessment, 1, $46-52$.

Martin, D. J., Garske, J. P., \& Davis, M. K. (2000). Relation of the therapeutic alliance with outcome and other variables: A meta-analytic review. Journal of Consulting and Clinical Psychology, 68, 438 - 450.

Meyer, B., Pilkonis, P. A., Krupnick, J. L., Egan, M. K., Simmens, S. J., \& Sotsky, S. M. (2002). Treatment expectancies, patient alliance, and outcome: Further analyses from the National Institute of Mental Health Treatment of Depression Collaborative Research Program. Journal of Consulting and Clinical Psychology, 70, 1051-1055.

Muran, J. C., Segal, Z. V., Samstag, L. W., \& Crawford, C. E. (1994) Patient pretreatment interpersonal problems and therapeutic alliance in short-term cognitive therapy. Journal of Consulting and Clinical Psychology, 62, 185-190.

Murphy, P. M., Cramer, D., \& Lillie, F. J. (1984). The relationship between curative factors perceived by patients in their psychotherapy and treatment outcome: An exploratory study. British Journal of Medical Psychology, 57, 187-192.

Norcross, J. C. (2001). Purposes, processes, and products of the task force on empirically supported therapy relationships. Psychotherapy, 38, 345-356.

Quintana, S. M., \& Meara, N. M. (1990). Internalization of therapeutic relationships in short-term psychotherapy. Journal of Counseling Psychology, 37, 123-130.

Raue, P. J., Castonguay, L. G., \& Goldfried, M. R. (1993). The working alliance: A comparison of two therapies. Psychotherapy Research, 3, 197-207.

Rude, S. S., \& Rehm, L. P. (1991). Response to treatment for depression: The role of initial status on targeted cognitive and behavior skills. Clinical Psychology Review, 11, 493-514.

Safran, J. D., Muran, J. C., Samstag, L. W., \& Stevens, C. (2002). Repairing alliance ruptures. In J. C. Norcross (Ed.), Psychotherapy relationships that work: Therapists contributions and responsiveness to patients (pp. 235-254). New York: Oxford University Press.

Safran, J. D., \& Segal, Z. V. (1990). Interpersonal process in cognitive therapy. New York: Basic Books.

Spangler, D. L., Baldwin, S. A., \& Agras, W. S. (2002). An examination of the mechanisms of action in cognitive-behavioral therapy for bulimia nervosa. Manuscript in preparation.

Spitzer, R. L., Williams, J. B., Gibbson, M., \& First, M. B. (1989). Structured Clinical Interview for the DSM-III-R. Washington, DC: American Psychiatric Association.

Tichenor, V., \& Hill, C. E. (1989). A comparison of six measures of working alliance. Psychotherapy: Theory, Research, and Practice, 26, 195-199.

Wilson, G. T. (1993). Assessment of binge eating. In C. G. Fairburn \& G. T. Wilson (Eds.), Binge eating: Nature, assessment, and treatment (pp. 227-249). New York: Guilford Press.

Wilson, G. T., Fairburn, C. C., Agras, W. S., Walsh, B. T., \& Kraemer, H. (2002). Cognitive- behavioral therapy for bulimia nervosa: Time course and mechanisms of change. Journal of Consulting and Clinical Psychology, 70, 267-274.

Wilson, G. T., Loeb, K. L., Walsh, T. B., Labouvie, E., Petkova, E., Liu, X., et al. (1999). Psychological versus pharmacological treatments of bulimia nervosa: Predictors and processes of change. Journal of Consulting and Clinical Psychology, 67, 451-459.

Received October 10, 2003

Revision received February 29, 2004

Accepted May 15, 2004 